needs and wishes remain poorly understood by health care professionals (Care Quality Commission, 2016). This study aims to bridge the gap in knowledge.

The Research Question The central question of this study is therefore; 'What matters most to homeless people in the UK as they consider end of life?' Only when the answers to this important question are understood, will the problem of homeless people dying without adequate support and with very little dignity or choice begin to be addressed.

Aim of Study The aim or purpose of this interpretive phenomenological study is therefore to explore the end of life priorities of a sample of homeless adults in the United Kingdom.

Methodology This qualitative $\mathrm{PhD}$ project is a phenomenological study underpinned by the philosophy of French phenomenologist, Maurice Merleau-Ponty. Data are being collected through in-depth, semi-structured, audio-recorded 1:1 interviews with homeless adults across several UK counties. Interviews are taking place at staffed centres providing services for older homeless adults. Data are being analysed iteratively using thematic analysis.

Results This $\mathrm{PhD}$ is a work in progress. Early findings will be shared.

Conclusion It is not yet possible to draw full conclusions from preliminary data. However, it is hoped that a deeper understanding of preferences and priorities will assist commissioners and healthcare professionals to plan and provide relevant palliative care services that genuinely meet the needs of the dying homeless.

The Florence Nightingale Foundation have part-funded this research.

\section{P-49 PALLIATIVE CARE SUPPORT FOR THE HOMELESS: THE RIGHT WAY, AT THE RIGHT TIME, IN THE RIGHT PLACE}

Jess Blandford, Jude Edwards. St Ann's Hospice, Cheadle, UK

\subsection{6/bmispcare-2017-hospice.76}

Background The CQC report 'A different ending: addressing inequalities in end of life care' highlighted that homeless people are not accessing palliative care and homeless staff are not equipped to deal with high levels of health and care needs. With a grant from the Albert Hunt Trust we developed training -without IT - that we can take to homeless organisations to equip staff to recognise signs that someone is in the palliative phase of their life, to know what to do, who to contact and how to access help.

Aims

- To increase access to hospice expertise.

- To increase understanding about palliative care by delivering a $1 \frac{1}{2}$ hour session to hostel staff, keyworkers, drug and alcohol teams, housing staff, food bank staff and volunteers.

- To provide practical support with our Health and Wellbeing Hub (the Hub) - a drop-in service staffed by a nurse - to the same venue as the training a month later. Methods We consulted with other hospices, a homeless GP practice, and homeless charities. We piloted the training with a homeless team and then took bookings from homeless organisations across our locality. Over a six-month period we will record the number of: referrals/contacts from homeless organisations compared to baseline figures staff we train/job role/organisation people accessing the Hub. We will evaluate: the training from feedback and case studies the Hub support from feedback and a record of any onward referrals/ signposting.

Conclusions There is an inequality in end of life care that needs addressing. From the pilot, the next steps to provide support to both staff and the homeless are: a further, more in depth, training programme to equip staff with better knowledge to improve the end of homeless peoples' lives to set up a combined clinic in a homeless GP practice with a Specialist Palliative Care Nurse.

\section{P-50 WORKING WITH TABOOS - THE DYING AND THE HOMELESS}

Kerry Macnish, Jo Anthony. Rowcroft Hospice, Torquay, UK

\subsection{6/bmjspcare-2017-hospice.77}

Background An identified unmet need for people who are homeless in Torbay to access end of life care services and hospice provision. Also identifying the end of life training needs of the workforce supporting homeless people across Torbay.

Aim To connect with homeless workforces to enable them to identify those individuals who would benefit from access to end of life care services and support.

Methods To identify the workforce across the private, statutory and voluntary sectors. To identify their learning needs and plan and deliver a programme of education. Participants completed a pre-and-post course evaluation of their knowledge and confidence. We received timely funding from HEE to enable this project.

Results

- 18 people working with homeless people attended two and half days bespoke end of life care training in 2016

- Participants recorded increased confidence and knowledge upon completion

- Greater connexion between hospice and homeless workforce and ongoing working relationships

- Improved recognition of the deterioration in this patient/ client population

- Increased confidence in leading discussions about future care needs with their clients and professional colleagues

- Received first referral to Rowcroft Hospice

- Course participants produced a locally mapped document of agencies supporting the homeless population for distribution

- Course participants undertook advance care planning discussions within their own families and across their community

- The local hostel committed to improving mechanisms for both support and supervision for their staff similar to the hospice model.

Conclusion The course became a vehicle for connecting local services involved with the homeless population of Torbay to make a change for the better. Participants felt enabled to recognise deterioration earlier, offer opportunities to discuss with patients/clients their thoughts and views about their future needs and care wishes. The course enabled us to build better joint working relationships, and increased engagement with the hospice services. 